ORIGINAL ARTICLE

\title{
Angiotensin converting enzyme gene polymorphism and cardiovascular morbidity and mortality: the Rotterdam Study
}

\author{
F A Sayed-Tabatabaei, A F C Schut, A Arias Vásquez, A M Bertoli-Avella, A Hofman, \\ J C M Witteman, C M van Duijn
}

J Med Genet 2005;42:26-30. doi: 10.1136/jmg.2004.022756

See end of article for authors' affiliations

Correspondence to:

F A Sayed-Tabatabaei,

Department of

Epidemiology and

Biostatistics, Erasmus

Medical Center, Postbus

$1738,3000 \mathrm{DR}$

Rotterdam, The

Netherlands;

f.sayed@erasmusmc.nl

Revised version received 7 July 2004

Accepted for publication

5 August 2004
Background: Findings on the association between the insertion/deletion (I/D) polymorphism of the angiotensin I-converting enzyme (ACE) gene and cardiovascular morbidity and mortality have been inconsistent. Considering the possible interaction between this polymorphism and smoking, we evaluated the association between ACE I/D polymorphism and myocardial infarction (MI), mortality due to coronary heart disease (CHD), and cardiovascular disease (CVD).

Methods: The study was performed within the Rotterdam Study, a population based cohort study. The ACE I/D polymorphism was determined for 6714 participants and smoking status recorded at baseline. Fatal and non-fatal Mls and mortality events were regularly recorded. Cox proportional hazard analysis was performed separately for current smokers and non-smokers. We used age as the follow up time, presenting age specific survivals.

Results: During follow up, $248 \mathrm{Mls}$ and 301 and 482 deaths, respectively, due to CHD and CVD occurred. There were no significant differences between the genotypes as regards $\mathrm{Ml}$ incidence. Among smokers, there was an increased risk of CHD and CVD mortality in carriers of the DD genotype compared to the II genotype, which diminished at later ages $(p<0.01$ for gene-age interaction). Subgroup analysis in a younger and older group (based on the median age of 68.2 years) showed a significantly increased risk of CVD mortality in the younger group (hazard ratio $=5.19 ; 95 \%$ confidence interval: 1.15 to 23.42 ).

Conclusions: This study showed that the ACE I/D polymorphism is not a strong risk factor for MI but its interaction with smoking might play a role in cardiovascular mortality especially at younger ages.
$\mathrm{T}$ he insertion/deletion (I/D) polymorphism in intron 16 of the angiotensin I-converting enzyme (ACE) gene has been associated with myocardial infarction $(\mathrm{MI})^{12}$ and coronary heart disease (CHD). ${ }^{3}{ }^{4}$ However, the findings of various large studies have been inconsistent. This situation is typical for genetic research of complex diseases, where genes may be involved in a disease through complex interactions with other genes and environmental factors. Using all the data we had available in the Rotterdam Study, we searched for modifiers of the relation between the ACE gene and serum ACE levels and found that smoking is the only other factor significantly influencing plasma ACE activity level. ${ }^{5}$ Further, we found interaction between ACE polymorphism and smoking in relation to carotid intima media thickness $(\text { IMT) })^{5}$ as well as systolic blood pressure. ${ }^{6}$ These findings prompted us to evaluate the effect of the ACE gene on MI as the main morbidity outcome of CHD, taking into account the putative interaction with smoking. We also investigated the association between the gene and mortality due to CHD as well as mortality from cardiovascular disease (CVD). We conducted our study in a large cohort which has been characterised for CVD and has been followed for over 8 years allowing us to assess the genotype associations at different ages.

\section{METHODS}

\section{Study population}

This study is embedded in the Rotterdam Study, a prospective population based cohort study of 7983 men and women aged 55 years or older, living in Rotterdam, the Netherlands. The study is designed to investigate the determinants of chronic diseases in the elderly and has been described in more detail elsewhere. ${ }^{7}$ Baseline data were collected between March 1990 and July 1993. The study has been approved by the Medical Ethics Committee of Erasmus University, and written informed consent was obtained from all participants. A trained research assistant interviewed all participants at home using computerised questionnaires. The information obtained included current health status, medical history, medication use, and smoking behaviour. In addition, during two visits to the research centre, established cardiovascular risk factors were measured.

\section{Follow up procedures}

The present analyses on MIs and CHD mortality are based on follow up data collected from baseline (1990-1993) until 1 January 2002. The information on cause specific mortality was obtained until 1 January 2000, and was the source of data on CVD mortality outcome. Information on the vital status of the participants was obtained at regular intervals from the municipal population registry. Fatal and non-fatal MIs were reported by general practitioners in the research area by means of a computerised system. An MI was considered fatal if death occurred within 28 days after the onset of symptoms. In the case of recurrent MI during follow up, the first event was used in the analysis. All reported events were verified by research physicians who collected information from the patients' medical records. This information also included copies of discharge letters for hospital

Abbreviations: $\mathrm{ACE}$, angiotensin l-converting enzyme; $\mathrm{CHD}$, coronary heart disease; CVD, cardiovascular disease; I/D, insertion/deletion; IMT, intima media thickness; MI, myocardial infarction 
Table 1 Demographic characteristics of subjects according to ACE I/D genotypes

\begin{tabular}{|c|c|c|c|}
\hline & \multicolumn{3}{|l|}{ ACE genotype } \\
\hline & II (n= 1473) & ID $(n=3358)$ & $\mathrm{DD}(\mathrm{n}=1883)$ \\
\hline Age (SD), years & $68.79(9.15)$ & $69.46(8.97)^{*}$ & $69.50(9.23)^{*}$ \\
\hline Men, $\%$ & 41.07 & 40.59 & 39.56 \\
\hline Body mass index (SD) & $26.34(3.84)$ & $26.26(3.72)$ & $26.35(3.66)$ \\
\hline Current smokers, $\%$ & 22.81 & 23.17 & 20.92 \\
\hline Total cholesterol (SD), mmol// & $6.58(1.26)$ & $6.62(1.20)$ & $6.60(1.22)$ \\
\hline $\mathrm{HDL}$ cholesterol (SD), $\mathrm{mmol} / \mathrm{l}$ & $1.34(0.36)$ & $1.35(0.35)$ & $1.35(0.37)$ \\
\hline Systolic BP (SD), mm Hg & $138.33(22.08)$ & $139.32(22.66)$ & $140.17(22.14)^{*}$ \\
\hline Diastolic BP (SD), $\mathrm{mm} \mathrm{Hg}$ & $73.60(11.78)$ & $73.69(11.69)$ & $73.96(11.29)$ \\
\hline Hypertension, \%† & 31.75 & $35.24^{*}$ & 34.71 \\
\hline Prevalence of $\mathrm{MI}, \% \ddagger$ & 11.52 & 13.24 & 12.27 \\
\hline Common carotid IMT (SD), $\mathrm{mm} \times 10^{-1}$ & $7.89(1.53)$ & $7.99(1.59)$ & $8.03(1.59)^{*}$ \\
\hline
\end{tabular}

admissions. All events were coded independently by two research physicians according to the International Statistical Classification of Diseases and Related Health Problems, 10th revision (ICD-10). ${ }^{8}$ CHD mortality is defined as ICD codes I20-I25, I46, I50, and R96. Cardiovascular (CVD) mortality includes all CHD deaths plus deaths due to stroke (I60-I64).

\section{Laboratory assessments}

Blood samples were drawn and serum and plasma were stored at $-80^{\circ} \mathrm{C}$. DNA was isolated from the blood samples using standard procedures (salting out method) ${ }^{9}$ and the II, ID, and DD genotypes were detected by using the polymerase chain reaction (PCR) technique according to the method of Lindpaintner et $a l^{10}$ with some modifications. Details of the genotyping method were published previously. ${ }^{5}$

\section{Statistical analyses}

Data were analysed using SPSS version 11.0.1 and S-PLUS version 6.0 for Windows. Hardy-Weinberg equilibrium was tested with the $\chi^{2}$ test. We used smoking as a dichotomous variable, grouping subjects in current smokers or non/former smokers. Survival time was calculated as the number of years from entry into the study until the time of the first event or until the end of follow up, whichever came first. We used Kaplan-Meier curves with age as the follow up time in the model, presenting age specific survivals. Cox proportional hazard analysis was used to calculate the hazard ratios between the genotype groups using the II genotype as the reference group. Data were analysed separately for current and non-smokers to examine effect modification by smoking. We also examined our hypothesis in gender subgroups, as one may expect differences between genders regarding the causal chain leading to CVD. Possible interactions were tested using multiplicative models.

\section{RESULTS}

The complete data of ACE genotyping and smoking status were available for 6714 subjects. Missing data were mainly due to logistic reasons. The distribution of the genotypes and allele frequencies were in Hardy-Weinberg equilibrium $(p=0.74)$. Table 1 shows the demographic characteristics of the participants by ACE genotype. The carriers of the D allele were somewhat older than the II carriers. Carriers of the DD genotype had a significantly higher mean systolic blood pressure as well as an increased mean of carotid IMT compared to the II carriers. Although the prevalence of hypertension was increased in both homozygote and heterozygote subjects for the D allele, this increase was significant only in the largest group, the heterozygotes. There was a tendency of higher prevalence of MI in carriers of the D allele, but the difference was not statistically significant (table 1). We excluded the subjects with prevalent MI in our further

Table 2 Incidence rates of $\mathrm{Ml}$ and mortality due to CHD and CVD according to ACE I/D genotypes

\begin{tabular}{|c|c|c|c|c|c|c|c|c|c|}
\hline \multicolumn{10}{|c|}{ A. In smoking groups adjusted for age and gender } \\
\hline & \multicolumn{9}{|c|}{ ACE genotypes } \\
\hline & \multicolumn{3}{|l|}{ All } & \multicolumn{3}{|c|}{ Non-smokers } & \multicolumn{3}{|l|}{ Smokers } \\
\hline & II $(n=1221)$ & ID $(n=2758)$ & $\mathrm{DD}(\mathrm{n}=1558)$ & II $(n=937)$ & ID $(n=2113)$ & $D D(n=1242)$ & II $(n=284)$ & ID $(n=645)$ & $D D(n=316)$ \\
\hline $\begin{array}{l}\text { Fatal and non-fatal MI } \\
\text { CHD mortality } \\
\text { CVD mortality }\end{array}$ & $\begin{array}{c}60(56) \\
63(67) \\
126(102)\end{array}$ & $\begin{array}{r}69(131) \\
58(151) \\
122(243)\end{array}$ & $\begin{array}{c}49(61) \\
57(83) \\
121(137)\end{array}$ & $\begin{array}{r}54(45) \\
61(54) \\
125(86)\end{array}$ & $\begin{array}{r}69(100) \\
57(120) \\
117(192)\end{array}$ & $\begin{array}{c}47(45) \\
52(66) \\
110(109)\end{array}$ & $\begin{array}{r}76(11) \\
49(13) \\
108(16)\end{array}$ & $\begin{array}{r}54(31) \\
55(31) \\
130(51)\end{array}$ & $\begin{array}{r}60(16) \\
68(17) \\
160(28)\end{array}$ \\
\hline
\end{tabular}

B. Gender groups adjusted for age

\begin{tabular}{|c|c|c|c|c|c|c|}
\hline & \multicolumn{6}{|c|}{ ACE genotypes } \\
\hline & \multicolumn{3}{|l|}{ Men } & \multicolumn{3}{|l|}{ Women } \\
\hline & II $(n=478)$ & ID $(n=1068)$ & $\mathrm{DD}(\mathrm{n}=581)$ & II $(n=743)$ & ID $(n=1690)$ & $\mathrm{DD}(\mathrm{n}=977)$ \\
\hline Fatal and non-fatal MI & $82(33)$ & $85(80)$ & $65(34)$ & $33(23)$ & $32(51)$ & $29(27)$ \\
\hline CHD mortality & $71(29)$ & $66(64)$ & $59(32)$ & $58(38)$ & $52(87)$ & $56(51)$ \\
\hline CVD mortality & 124 (39) & $126(93)$ & $120(50)$ & $127(63)$ & $119(150)$ & $122(87)$ \\
\hline
\end{tabular}

Values are incidence rates per 10000 person-years (number of events); CHD, coronary heart disease; CVD, cardiovascular disease; MI, myocardial infarction. 
A

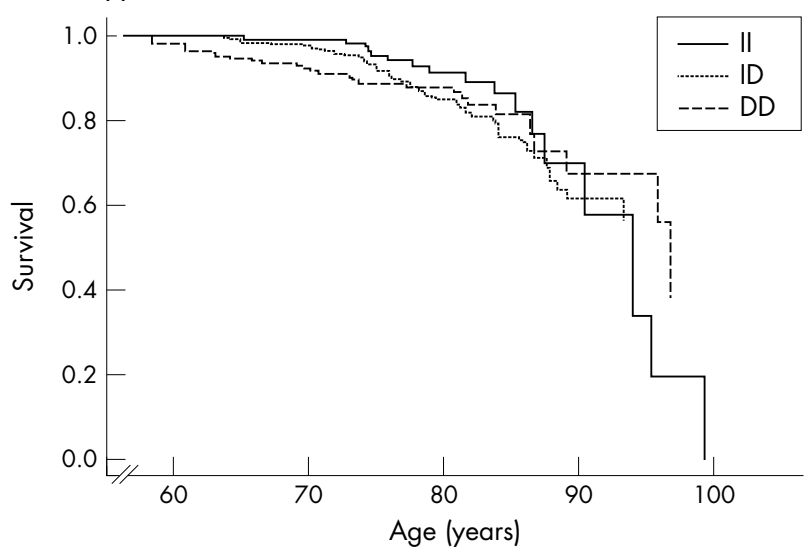

B

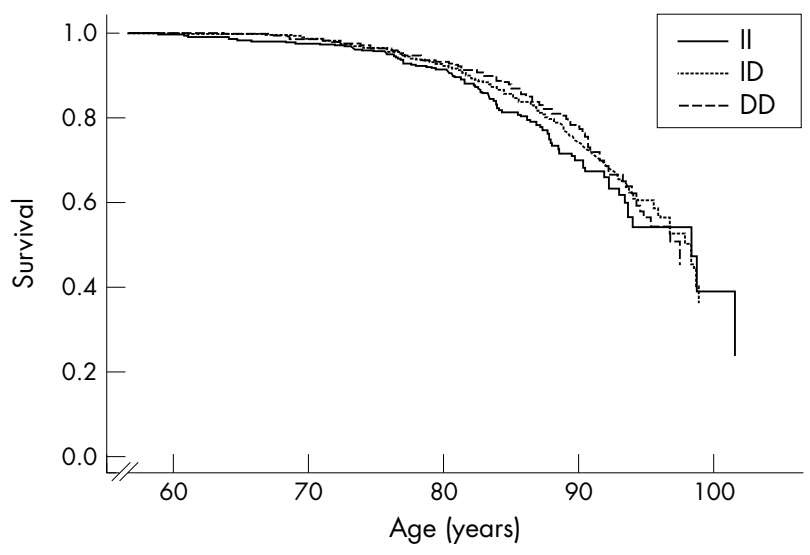

Figure 1 Age specific CHD mortality for different genotype groups in smokers (top) and non-smokers (bottom) adjusted for gender.

analysis as differential mortality may have occurred in this subgroup before the start of the study.

Mean follow up time for CHD was 8.4 years. During this period 248 persons had a first MI and 301 deaths due to CHD occurred. For the period of follow up for CVD mortality outcome $($ mean $=7.1$ years) 482 deaths caused by CVD occurred. Table $2 \mathrm{~A}$ presents the age and gender adjusted incidence rates by genotype. No obvious pattern was observed in the association between the genotypes and the risk of MI. Among smokers, the incidence rates for CHD and CVD mortality were higher in carriers of the DD genotype, while no such differences were seen in non-smokers. However, the differences in incidence rates between the genotypes were not statistically significant (table 2A). Further analyses, stratified by gender, did not reveal any evidence for increasing incidence rates associated with genotypes in men or women (table $2 \mathrm{~B}$ )

When considering age specific mortality (figs 1 and 2), an increased risk of CHD and CVD mortality in the DD genotype group was observed only in smokers. The effect of the gene diminished with age. No such effect was seen in nonsmokers (figs 1 and 2). The interaction between the ACE genotypes and age was statistically significant in smokers $(\mathrm{p}<0.01)$, but not in non-smokers or the total group (table 3$)$. The same pattern of genotype-age interaction was observed in both men and women. No interaction between the genotypes and gender was observed in any of the smoking categories (data not shown).

With this observation, we retested our hypothesis separately for the groups younger and older than the median age
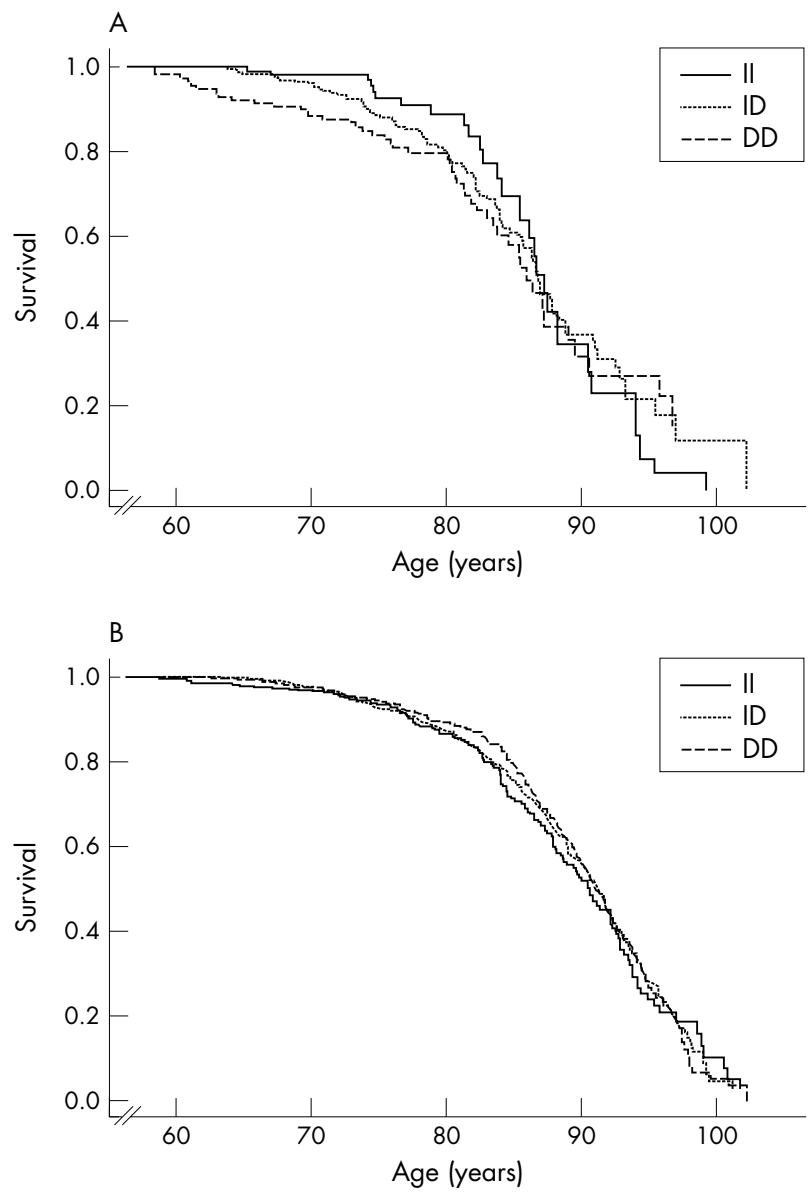

Figure 2 Age specific CVD mortality for different genotype groups in smokers (top) and non-smokers (bottom) adjusted for gender.

of the population (68.2 years) using the age as a time dependent variable, that is, when a participant in the younger group reached the age of 68.2 he was counted in the older group. Table 4 presents the hazard ratios of CHD and CVD mortality for the ID and DD genotypes in comparison to the II genotype in different subgroups. In the younger group, the risk of CVD mortality showed a significant difference between the genotypes in smokers $(p=0.03)$ but not in non-smokers $(p=0.60)$, men $(p=0.25)$, or women $(p=0.45)$. Higher risk of mortality was observed in those with the ID and DD genotypes compared to the II genotype among smokers in this group (table 4). In a multiplicative

Table 3 Test of interaction between ACE I/D genotypes, smoking status, and age

\begin{tabular}{|c|c|c|c|c|}
\hline & \multicolumn{2}{|c|}{ CHD mortality } & \multicolumn{2}{|c|}{ CVD mortality } \\
\hline & ID & DD & ID & DD \\
\hline $\begin{array}{l}\text { Gene-age interaction* } \\
\text { p (smokers) } \\
\text { p (non-smokers) } \\
\text { p (total group) }\end{array}$ & $\begin{array}{l}0.01 \\
0.75 \\
0.24\end{array}$ & $\begin{array}{r}<0.01 \\
0.58 \\
0.20\end{array}$ & $\begin{array}{r}<0.01 \\
0.63 \\
0.39\end{array}$ & $\begin{array}{r}<0.01 \\
0.15 \\
0.32\end{array}$ \\
\hline $\begin{array}{l}\text { Gene-smoking interaction } \dagger \\
\mathrm{p} \text { (below median of age) } \neq \\
\mathrm{p} \text { (above median of age) } \ddagger \\
\mathrm{p} \text { (total group) }\end{array}$ & $\begin{array}{l}0.13 \\
0.46 \\
0.27\end{array}$ & $\begin{array}{l}0.06 \\
0.83 \\
0.42\end{array}$ & $\begin{array}{l}0.24 \\
0.65 \\
0.50\end{array}$ & $\begin{array}{l}0.05 \\
0.98 \\
0.39\end{array}$ \\
\hline
\end{tabular}

*Adjusted for gender; †adjusted for age and gender; fmedian age $=68.2$ years . 
Table 4 Hazard ratios of mortality due to CHD and CVD according to ACE I/D genotypes adjusted for age and gender

\begin{tabular}{|c|c|c|c|c|c|c|}
\hline & \multicolumn{3}{|l|}{ CHD mortality } & \multicolumn{3}{|l|}{ CVD mortality } \\
\hline & ID $(95 \% \mathrm{Cl})$ & $\mathrm{DD}(95 \% \mathrm{CI})$ & p (Wald test) & ID $(95 \% \mathrm{Cl})$ & DD (95\% Cl) & $p$ (Wald test) \\
\hline \multicolumn{7}{|c|}{ Below median age* } \\
\hline Smokers & $2.78(0.33$ to 23.10$)$ & 7.33 (0.92 to 58.65$)$ & 0.06 & 1.91 (0.41 to 9.02$)$ & $5.19(1.15$ to 23.42$)$ & 0.03 \\
\hline Non-smokers & $0.43(0.15$ to 1.29$)$ & 0.74 (0.25 to 2.22$)$ & 0.32 & $0.63(0.25$ to 1.60$)$ & $0.89(0.33$ to 2.36$)$ & 0.60 \\
\hline Men & $0.98(0.29$ to 3.25$)$ & $2.02(0.62$ to 6.57$)$ & 0.26 & $0.98(0.37$ to 2.61$)$ & 1.83 (0.69 to 4.88$)$ & 0.25 \\
\hline Women & 0.50 (0.12 to 1.98$)$ & 1.06 (0.29 to 3.97$)$ & 0.47 & $0.73(0.21$ to 2.59$)$ & $1.47(0.43$ to 5.03$)$ & 0.45 \\
\hline \multicolumn{7}{|c|}{ Above median age ${ }^{*}$} \\
\hline Smokers & 1.21 (0.69 to 2.13 ) & $0.81(0.41$ to 1.61$)$ & 0.33 & 1.14 (0.72 to 1.78 ) & $0.99(0.59$ to 1.65$)$ & 0.73 \\
\hline Non-smokers & $0.97(0.74$ to 1.25 ) & 0.88 (0.65 to 1.17 ) & 0.63 & 1.03 (0.83 to 1.27$)$ & 0.98 (0.77 to 1.23 ) & 0.87 \\
\hline Men & 1.04 (0.74 to 1.44 ) & 0.85 (0.58 to 1.25 ) & 0.49 & 1.13 (0.85 to 1.51$)$ & $1.06(0.77$ to 1.45$)$ & 0.67 \\
\hline Women & $0.93(0.68$ to 1.28$)$ & 0.81 (0.56 to 1.16$)$ & 0.48 & 0.94 (0.74 to 1.19$)$ & $0.89(0.69$ to 1.16$)$ & 0.69 \\
\hline
\end{tabular}

The ll genotype used as the reference group. CHD, coronary heart disease; CVD, cardiovascular disease; $95 \% \mathrm{Cl}, 95 \%$ confidence interval. ${ }^{*}$ Median age $=68.2$ years.

model, gene-smoking interaction was borderline significant $(p=0.06)$ in CHD mortality and significant $(p=0.05)$ in CVD mortality among the younger group (table 3 ). There was no evidence of association between the genotypes and the mortality risks in the older group in any of the smoking or gender categories (table 4).

\section{DISCUSSION}

In this large population based cohort study, we observed an increased risk of cardiovascular mortality for carriers of the D allele of the ACE I/D polymorphism among smokers. This difference was only observed in younger people and diminished at later ages. No association was observed between the ACE genotype and MI.

The ACE gene became one of the most studied candidate genes in relation to CVD after Rigat et al reported that more than half of the variance of plasma ACE concentration is under the influence of the I/D polymorphism in this gene. ${ }^{11}$ Although several studies showed a positive association between the $\mathrm{D}$ allele and cardiovascular outcomes, findings have been inconsistent. A meta-analysis showed that smaller studies tend to show a stronger association and concluded that in general the association is weak. ${ }^{12}$ However, interactions between genetic and environmental factors are expected in all complex diseases and may partly explain the previous inconsistencies. A possible interaction between smoking and the I/D polymorphism in relation to carotid IMT $^{5}$ and systolic blood pressure ${ }^{6}$ prompted the present study to test the same interaction effect on the risk of MI as the main morbidity outcome of CHD, as well as mortality due to CHD and CVD.

Our findings in this cohort study were in line with the findings from other large studies, ${ }^{10}{ }^{13} 14$ showing no strong association between ACE I/D and MI. Hibi et al showed a smoking associated effect of the ACE genotype on the severity of coronary atherosclerosis. ${ }^{15}$ Although we confirmed the same interaction in our previous findings, ${ }^{56}$ we did not observe any evidence for such an interaction in relation to MI in this study.

Considering mortality, the main differences between the genotypes were observed at earlier ages in our population. At older ages, the effect of the gene apparently diminished. One may argue that the older individuals are the survivors from a larger cohort and have been subject to selective mortality. ${ }^{16}$ We previously reported an interaction between age and ACE I/D genotypes in association with carotid stiffness. ${ }^{17}$ An age dependent association has also been found in the other genes involved in CVD, for instance Apo-E. ${ }^{18}{ }^{19}$ Although chance might play a role in our observations, the possibility remains that the interaction between the D allele and smoking in fact has a role in younger age groups, but we are not able to fully demonstrate it in our study population. In other words, if there is a real effect of the D allele and smoking at young ages, it might very well have happened before the start of our study, which only includes a cohort aged 55 years and over.

The mechanism by which the ACE I/D polymorphism may affect cardiovascular morbidity and mortality is unclear. It has been shown that the DD carriers convert angiotensin I at higher rates. ${ }^{2021}$ The vasoconstrictor effect of angiotensin II in addition to its role in vascular smooth muscle cell growth and hypertrophic changes of the vessel wall ${ }^{22}{ }^{23}$ were speculated to be the possible pathway. It is also suggested that ACE might play an important role in inflammatory responses. ${ }^{24}$ Furthermore, smoking increases ACE gene expression and the activity of the enzyme. ${ }^{525}{ }^{26}$ Considering the complexity of CVD, a combination of several different pathways could be involved in the present observations and the mechanisms involved in cardiovascular events at younger ages could be different from those in later life. Similarly, differences in causal chains in different samples could be the main reason for controversial findings, but discovery of the whole underlying system is beyond the scope of a single observational study.

In conclusion, our study showed that the I/D polymorphism of the ACE gene is not a strong risk factor for MI but its interaction with smoking might play a role in mortality from CVD especially at an earlier age.

\section{ACKNOWLEDGMENTS}

The contributions of the general practitioners and pharmacists of the Ommoord district to the Rotterdam Study are gratefully acknowledged.

\section{Authors' affiliations}

F A Sayed-Tabatabaei, A F C Schut, A Arias Vásquez, A M BertoliAvella, A Hofman, J C M Witteman, C M van Duijn, Department of Epidemiology and Biostatistics, Erasmus Medical Center, Rotterdam, The Netherlands

This study was supported by the Netherlands Organization for Scientific Research (NWO), grant 904-61-196. The study utilised facilities funded by the Centre for Medical Systems Biology. The Rotterdam Study is supported by the Erasmus Medical Center and Erasmus University Rotterdam, the Netherlands Organization for Scientific Research (NWO), the Netherlands Organization for Health Research and Development (ZonMw), the Research Institute for Diseases in the Elderly (RIDE), the Ministry of Education, Culture and Science, the Ministry of Health, Welfare and Sports, the European Commission (DG XII), and the Municipality of Rotterdam.

Competing interests: none declared

\section{REFERENCES}

1 Samani NJ, Thompson JR, O'Toole L, Channer K, Woods KL. A meta-analysis of the association of the deletion allele of the angiotensin-converting enzyme gene with myocardial infarction. Circulation 1996;94:708-12. 
2 Cambien F, Poirier O, Lecerf L, Evans A, Cambou JP, Arveiler D, Luc G, Bard JM, Bara L, Ricard S, Tiret L, Amouyel P, Alhenc-Gelas F, Soubrier F. Deletion polymorphism in the gene for angiotensin-converting enzyme is a potent risk factor for myocardial infarction. Nature 1992;359:641-4.

3 Mattu RK, Needham EW, Galton DJ, Frangos E, Clark AJ, Caulfield M. A DNA variant at the angiotensin-converting enzyme gene locus associates with coronary artery disease in the Caerphilly Heart Study. Circulation 1995;91:270-4.

4 Nakai K, Itoh C, Miura Y, Hotta K, Musha T, Itoh T, Miyakawa T, Iwasaki R, Hiramori K. Deletion polymorphism of the angiotensin l-converting enzyme gene is associated with serum ACE concentration and increased risk for CAD in the Japanese. Circulation 1994;90:2199-202.

5 Sayed-Tabatabaei FA, Schut AF, Hofman A, Bertoli-Avella AM, Vergeer J Witteman JC, van Duijn CM. A study of gene-environment interaction on the gene for angiotensin converting enzyme: a combined functional and population based approach. J Med Genet 2004;41:99-103.

6 Schut AF, Sayed-Tabatabaei FA, Witteman JC, Bertoli-Avella AM, Vergeer J Pols HAP, Hofman A, Deinum J, van Duijn CM. Smoking-dependent effects of the angiotensin-converting enzyme gene insertion/deletion polymorphism on blood pressure. J Hypertens 2004;22:313-9.

7 Hofman A, Grobbee DE, de Jong PT, van den Ouweland FA. Determinants of disease and disability in the elderly: the Rotterdam Elderly Study. Eur J Epidemiol 1991;7:403-22.

8 WHO. International statistical classification of diseases and related health problems, Vol 1. 10th ed. Geneva: WHO, 1992.

9 Miller SA, Dykes DD, Polesky HF. A simple salting out procedure for extracting DNA from human nucleated cells. Nucleic Acids Res 1988;16:1215.

10 Lindpaintner K, Pfeffer MA, Kreutz R, Stampfer MJ, Grodstein F, LaMotte F, Buring J, Hennekens $\mathrm{CH}$. A prospective evaluation of an angiotensinconverting-enzyme gene polymorphism and the risk of ischemic heart disease. N Engl J Med 1995;332:706-11.

11 Rigat B, Hubert C, Alhenc-Gelas F, Cambien F, Corvol P, Soubrier F. An insertion/deletion polymorphism in the angiotensin l-converting enzyme gene accounting for half the variance of serum enzyme levels. J Clin Invest 1990;86:1343-6.

12 Agerholm-Larsen B, Nordestgaard BG, Tybjaerg-Hansen A. ACE gene polymorphism in cardiovascular disease: meta-analyses of small and large studies in whites. Arterioscler Thromb Vasc Biol 2000;20:484-92.

13 Holmer SR, Bickeboller H, Hengstenberg C, Rohlmann F, Engel S, Lowel H, Mayer B, Erdmann J, Baier C, Klein G, Riegger GA, Schunkert H. Angiotensin converting enzyme gene polymorphism and myocardial infarction: a large association and linkage study. Int J Biochem Cell Biol 2003;35:955-62

14 Agerholm-Larsen B, Nordestgaard BG, Steffensen R, Sorensen TI, Jensen G, Tybjaerg-Hansen A. ACE gene polymorphism: ischemic heart disease and longevity in 10,150 individuals. A case-referent and retrospective cohort study based on the Copenhagen City Heart Study. Circulation 1997;95:2358-67.

15 Hibi K, Ishigami T, Kimura K, Nakao M, Iwamoto T, Tamura K, Nemoto T, Shimizu T, Mochida Y, Ochiai H, Umemura S, Ishii M. Angiotensin-converting enzyme gene polymorphism adds risk for the severity of coronary atherosclerosis in smokers. Hypertension 1997;30:574-9.

16 Evans AE, Poirier O, Kee F, Lecerf L, McCrum E, Falconer T, Crane J, $\mathrm{O}^{\prime}$ Rourke DF, Cambien F. Polymorphisms of the angiotensin-convertingenzyme gene in subjects who die from coronary heart disease. Q J Med 1994:87:211-4.

17 Mattace-Raso FU, van der Cammen TJ, Sayed-Tabatabaei FA, van Popele NM, Asmar R, Schalekamp MA, Hofman A, van Duijn CM, Witteman JC. Angiotensin-converting enzyme gene polymorphism and common carotid stiffness. The Rotterdam study. Atherosclerosis 2004; 174:121-6

18 Ilveskoski E, Perola M, Lehtimaki T, Laippala P, Savolainen V, Pajarinen J, Penttila A, Lalu KH, Mannikko A, Liesto KK, Koivula T, Karhunen PJ. Agedependent association of apolipoprotein $\mathrm{E}$ genotype with coronary and aortic atherosclerosis in middle-aged men: an autopsy study. Circulation 1999; 100:608-13.

19 Slooter AJ, Cruts M, Van Broeckhoven C, Hofman A, van Duijin CM. Apolipoprotein E and longevity: the Rotterdam Study. J Am Geriatr Soc 2001;49:1258-9.

20 Buikema H, Pinto YM, Rooks G, Grandiean JG, Schunkert H, van Gilst WH. The deletion polymorphism of the angiotensin-converting enzyme gene is related to phenotypic differences in human arteries. Eur Heart $J$ 1996; 17:787-94.

21 Ueda S, Elliott HL, Morton JJ, Connell JM. Enhanced pressor response to angiotensin I in normotensive men with the deletion genotype (DD) for angiotensin-converting enzyme. Hypertension 1995;25:1266-9.

22 Berk BC, Vekshtein V, Gordon HM, Tsuda T. Angiotensin II-stimulated protein synthesis in cultured vascular smooth muscle cells. Hypertension 1989:13:305-14.

23 Patel MK, Betteridge $\amalg$, Hughes AD, Clunn GF, Schachter M, Shaw RJ, Sever PS. Effect of angiotensin II on the expression of the early growth response gene c-fos and DNA synthesis in human vascular smooth muscle cells. J Hypertens 1996;14:341-7.

24 Brull DJ, Sanders J, Rumley A, Lowe GD, Humphries SE, Montgomery HE. Impact of angiotensin converting enzyme inhibition on post-coronary artery bypass interleukin 6 release. Heart 2002;87:252-5.

25 Zhang S, Day I, Ye S. Nicotine induced changes in gene expression by human coronary artery endothelial cells. Atherosclerosis 2001;154:277-83.

26 Sugiyama Y, Yotsumoto H, Okabe T, Takaku F. Measurement of angiotensinconverting enzyme activity in intact human alveolar macrophages and effect of smoking. Respiration 1988;53:153-7. 